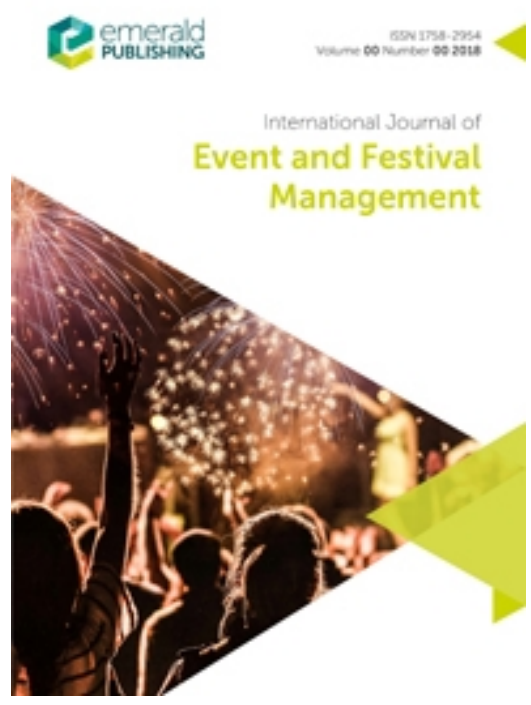

\title{
IMPACTS OF A HEALTH CRISIS ON MUSIC FESTIVALS: A QUALITATIVE APPROACH
}

\begin{tabular}{|r|l|}
\hline Journal: & International Journal of Event and Festival Management \\
\hline Manuscript ID & IJEFM-12-2020-0081.R2 \\
\hline Manuscript Type: & Research Paper \\
\hline Keywords: & $\begin{array}{l}\text { health crisis, Viña Rock Festival, STAKEHOLDERS, SET, VICE model, } \\
\text { FESTIVALS }\end{array}$ \\
\hline \multicolumn{2}{r}{} \\
\hline
\end{tabular}

\section{SCHOLARONE \\ Manuscripts}

\section{Citation}

Orea-Giner, A., González-Reverté, F. and Fuentes-Moraleda, L. (2022), "Impacts of a health crisis on music festivals: a qualitative approach", International Journal of Event and Festival Management, Vol. ahead-of-print No. ahead-of-print. https://doi.org/10.1108/ IJEFM-12-2020-0081 


\section{IMPACTS OF A HEALTH CRISIS ON MUSIC FESTIVALS: A QUALITATIVE APPROACH}

\section{Originality}

The most important contribution of this research is the theoretical model proposed to analyse stakeholders' perception of the event celebration in a context of a health crisis. The model also considers different moments of the social exchange. The theoretical approaches considered (SET and VICE models) allow analysing the stakeholder's perception of a case study of a music festival (Viña Rock Festival, Spain). The emerging and central role of the cooperation between stakeholders constitutes another notable contribution to the literature.

\section{Purpose}

This research explores the consequences of a health crisis provoked by a pandemic scenario on music festival impacts considered by the stakeholders involved. The purpose is to identify the perceptions from the stakeholders' point of view (host community, public and private sector) and to identify the impacts generated before and after a health crisis regarding the celebration of a festival.

\section{Methodology}

The study offers a holistic insight into impact research by music festivals. The methodology implemented is based on qualitative techniques. By conducting 20 in-depth interviews with essential stakeholders, it is possible to determine their perceptions of the impact of the event and the effects of a health crisis.

\section{Findings}

The results allow detecting a gap between internal and external stakeholders due to poor communication and planning of the event. The results show that a health crisis provokes negative impacts on the economic benefits of events' organisation. However, the cultural city's identity suffers an important damage that it is difficult to over. The community and visitors are the stakeholders that suffer a detrimental impact on their experience when attending the festival, considering the security measures. Moreover, results allow us to identify practical implications for event management and planning in a health crisis scenario.

Keywords: stakeholders; health crisis; SET; VICE; Festival; COVID-19; Viña Rock Festival.

\section{Introduction}

Risk management is a crucial element of events management (Quinn, 2013). Health crisis impacts are evident in the events' sector because of the necessity to adapt to the environment of work and the way of offering the services (Ponting, 2021). Because of the characteristics of events, health crisis poses a challenge for international event managers. Under these conditions, anticipating and preparing to deal with the threat of crises precipitated by catastrophes is a 
significant challenge facing event management. Previous studies have focused primarily on analysing the impacts caused by events from different perspectives (Morales Pérez and Pacheco Bernal, 2017; Getz and Page, 2016; Weidenfeld and Leask, 2013; O'Sullivan and Jackson, 2002). Aspects such as the image they project, the economic impacts that they are associated with, or the impact on urban regeneration (Getz, 2008), as well as the social and cultural aspects of the local community (González Reverté and Morales Pérez, 2017) have also been widely studied. However, there is hardly any literature focused on impacts derived from the rescheduling of global catastrophes, such as COVID-19 outbreaks. Cultural and social impacts associated with the cancellation and/or rescheduling of the event's agendas are crucial topics to examine due to a health crisis, such as COVID-19 outbreaks. In addition, it is essential to analyse the effects of a health crisis on public health recommendations for these events since festivals need to have regulations regarding health and safety due to the large number of people attending (Getz and Page, 2016).

Implementing both the theory of social exchange (SET) and VICE (Visitor, Industry, Community and Environment) model is appropriate for studying the local impact of a music festival and the consequences of a health crisis, such as the COVID-19 pandemic. Previous studies have applied the theory of social exchange (SET) to analyse the effects of tourism on the local community and stakeholders (Monterrubio et al., 2018). This theory is complemented by applying the VICE model, proposed by Van Niekerk and Coetzee (2013). The VICE model considers the exchange relationships between stakeholders and the local community, favouring the identification of the impacts caused by the holding of events (Van Niekerk and Getz, 2016; Collins and Cooper, 2016; Dodds and Walsh, 2018; Liu et al., 2018). The combination of the VICE Model and SET may theoretically support a better understanding of stakeholder perceptions about the impacts of a music festival under a new risk scenario.

The paper aims to analyse the perceived impacts and consequences caused by a health crisis on an event taking place for almost 25 years. Specifically, we analysed the festival named 'Viña Rock', held in Villarrobledo (Albacete, Spain) since 1996. It is one of the most important festivals in Spain and is considered of regional tourist interest. In 2019, it was the second-largest in Spain in terms of attendees, attracting 240,000 people and generating an economic impact of 22 million euros that created 2,200 direct jobs and 3,000 indirect jobs (Manjavacas, 2019). Viña Rock 2020 was scheduled for the $25^{\text {th }}$ anniversary of the festival, running from 30 April to 2 May 2020. After, it was reprogrammed to October 2021. However, due to the health situation, the event is schedlued to be staged again on 28-30 April 2022. This paper aims to explore stakeholders' views (host community, public and private sector) regarding significant festival impacts and the consequences of a health crisis, such as COVID-19.

The research was done by performing a qualitative study to analyse the impacts caused by the event and the effects of a health crisis to identify stakeholders' opinions. The study provides answers to the following questions:

RQ1. From a stakeholder's perspective, what are the festival's main perceived impacts on the industry before and after a health crisis? 
RQ2. From a stakeholder's perspective, what are the festival's main perceived impacts on the community before and after a health crisis?

RQ3. From a stakeholder's perspective, what are the festival's main perceived impacts on the visitors before and after a health crisis?

RQ4. From a stakeholder's perspective, what are the festival's main perceived impacts on the environment before and after a health crisis?

\section{Literature review}

\subsection{Health crisis on programmed cultural events: COVID-19 impacts and the perspective of stakeholders}

Parent and Smith-Swan (2013) identified that the critical skill of events' managers is to identify and reduce the risks linked to pandemics when organising events. Due to the inevitable interrelationship between stakeholders during events' celebrations, it is also possible to identify other impacts and those related to health. These impacts derived from a health crisis are connected to the event industry and the tourist industry linked to the assistance to events (Mohanty et al., 2020). The tourist industry has suffered devastating consequences from the effects of COVID-19 (Hoque et al., 2020; VillacéMolinero et al., 2021). COVID-19 has impacted tourists' consumption and behaviour because their lifestyle can influence decisions made when travelling in these circumstances (Wen et al., 2020). As a leading country in the world in terms of tourism competitiveness, receipts, and inbound tourists, the repercussions for Spain have been enormous. Gil-Alana and Poza (2020) results show the need for strong policy measures to bring the series back to their long-term projections.

As said before, the adverse effects of the pandemic do affect not only the tourism sector but also cause negative impacts on other sectors of the economy that can create income imbalances and lead to a social divide (Polyzos et al., 2020). Under these circumstances, event tourism is one of the areas that has suffered significant losses due to the pandemic scenario (Mohanty et al., 2020; Gössling et al., 2020). The spread of COVID-19 due to the celebration of festivals has been studied by Jitsuk et al. (2020). They confirmed that mass events, where there is direct contact between travellers, present a serious risk of spreading the disease and causing outbreaks in the local population due to close contact with the tourists who attend these events.

Among the measures identified in the literature, the attention paid to local communities where events are held and the celebration of virtual festivals stands out (Davies, 2020). Therefore, it is recommended that the number of participants is reduced and that virtual assistance be introduced to reduce physical contact (McCloskey et al., 2020). McCloskey et al. (2020) propose a 
series of measures to ensure risk control by festival managers during the COVID-19 pandemic. Regarding security in events during a health crisis, Ludvigsen and Hayton (2020) remark that one of the most critical security measures is social distancing until a large population is vaccinated. Besides, the risk control measures on festivals must include the importance of the stakeholders in the whole process. The measures need to be aligned with public health needs and inform the local population and the stakeholders about the situation. Therefore, event professionals need to demonstrate that they have the skills to deal with safety and security measures after a crisis, such as that caused by COVID-19 (Seraphin, 2020).

\subsection{The theory of social exchange (SET) and the VICE model application on programmed cultural events}

The impacts generated by the celebration of events and their measurement can be considered from different perspectives (Picard and Robinson, 2006; Rollins and Delamere, 2007). Sociocultural impacts have been analysed by applying different methodologies to analyse tourist destinations (Fredline et al., 2003). Furthermore, the study of residents' perceptions is useful for event organisers to evaluate the effects of their management at the local level, in order to modify or adapt the festival design and meet the local community's needs (Morales Pérez and Pacheco Bernal, 2017). Besides, González Reverté and Morales Pérez (2017) developed an analysis of the sociocultural impacts of events held in tourist destinations in Catalonia. González Reverté and Morales Pérez (2017) relate sociocultural impacts of events celebrated in Spain as catalysts for (1) strengthening the community destination and the identity of the local and regional culture; (2) strengthening the sense of community and social capital; (3) strengthening the sense of well-being in the local community during the celebration of events. Furthermore, they highlighted that those events serve as a catalyst for the social and cultural values of the local community and are a means of showcasing them (González Reverté and Morales Pérez, 2017).

In this paper, we consider two different but complementary theoretical approaches: SET and VICE model. The application of both SET and the VICE model, it is possible to identify the interest in analysing the perspective of stakeholders (Rollins and Delamere, 2007; Bagiran and Kurgun, 2013; Van Niekerk and Getz, 2016; Yolal et al., 2016; Liu et al., 2018; Zhang et al., 2020). Besides, the negative impacts on the environment provoked by the events are also considered (Praveen and Deepak, 2016; Collins and Cooper, 2017; Dodds and Walsh, 2018; Liu et al., 2018). Both theoretical contributions help us to analyse the relationships of exchange focused on stakeholders' social benefits and costs to achieve sustainability in events.

The VICE model refers to the business and tourism industries: festivals can only be profitable and prosperous if money enters the local economy through domestic or international visitors (Van Niekerk and Coetzee, 2013). The VICE model has been used in previous research to analyse the sustainability of 
events (Duran et al., 2014) and the concern for sustainability (Van Niekerk and Coetzee, 2013), community participation in events (Scholtz et al., 2019), as well as the experience of visitors (Barber et al., 2014; Kinnunen and Haahti, 2015). The economic impact of festivals has been addressed under the assumption that the economic benefits of festivals are one of the most important reasons for organising a festival in the first place (Crompton and McKay, 1997; Thrane, 2002). It is essential to distinguish between the socio-economic, cultural, and environmental impacts of festivals (Andereck and Vogt, 2000; Harrill, 2004; Bimonte and Punzo, 2016) that determine the host community's well-being (Dolan et al., 2011; Kim et al., 2013; Woo et al., 2015; Uysal et al., 2016; Stienmetz et al., 2020; Tan et al., 2020).

Because of these considerations about the conduct of events after a health crisis, the theory of social exchange (SET) offers advantages over analysing local community and stakeholder perception. SET derives from the proposals of Homans (1961), Kelley and Thibaut (1959) and Blau (1964), who suggest an interrelationship between concepts such as norms, cohesion, power and others. Social interchanges are produced when individuals look for mutual benefits, and social exchanges are produced, prioritising the concepts of reciprocity and negotiation. However, it is also possible that exchanges take place from rationality, altruism, and competition. Following this theory, it is considered that, although the economic value of the exchanged resources can be considered, it is also possible to consider symbolic values that are not only about material resources (Monterrubio et al., 2018).

SET connects the VICE model through the importance of analysing the stakeholders' perspectives about the events' impacts in different moments. By understanding stakeholders' attitudes in the context of programmed events, partners involved in the exchange can strategically adjust social relations to achieve mutually desired outcomes and impacts. Therefore, both theoretical proposals (VICE and SET) could be incorporated in any model that attempts to analyse the impacts of programmed events from the stakeholder's perspective. This fact may provide researchers and the event industry with a better theoretical understanding of why the industry, community, visitors, and environment are not disposed toward event programmed development (positively or negatively). In an attempt to fill the gaps identified above, the study is based on a model developed around the core concepts of SET (Figure 1)

Figure 1. Integration of VICE model and SET 


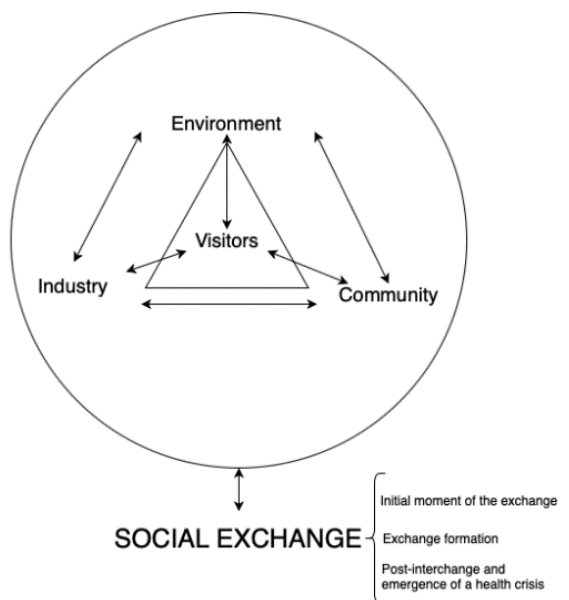

Source: Based on Van Niekerk and Coetzee (2013) and Monterrubio et al., (2018)

The considered proposal suggests that impacts of programmed events are influenced by social exchange among community, industry and visitors, which has different social, economic and environmental impacts. The model further proposes that the impacts have to be considered according to the different moments of the social exchange: (i) initial moment of the exchange (Getz, 2008; González Reverté and Morales Pérez, 2017); (ii) exchange formation (Rollins and Delamere, 2007; O'Sullivan and Jackson, 2002; Van Niekerk and Coetzee, 2013; Bagiran and Kurgun, 2013; Chirieleison and Scrucca, 2017; Liu et al., 2018); (iii) post-interchange and the emergence of a health crisis (Gössling et al., 2020; Kachanoff et al., 2020; Nepal, 2020; Rowen, 2020).

Additionally, it is vital to consider the perception according to the type of stakeholders involved in the festival. Van Niekerk and Getz (2016) made a clear distinction between internal and external festival stakeholders. Internal festival stakeholders (employees, owners/shareholders, senior management) were identified as those stakeholder groups or individuals inside the organisation that affect or are affected by the decisions of the festival. On the other hand, external festival stakeholders (customers, government, suppliers, special interest groups, competitors) are outside the festival organisation but still affected.

According to Gursoy et al. (2004), examining stakeholder perceptions of the impacts of festivals has been limited. This qualitative study includes the analysis of the industry and community perspective and the public sector perception to fill this gap. About the environmental impacts, studies have been developed to understand and measure them to provide a method to evaluate these results for event managers (Collins and Cooper, 2017). In promoting positive impacts on the environment, the stimulation of stakeholders is fundamental (Dodds and Walsh, 2018). Thus, it is essential to analyse the aspects related to waste, noise, and traffic management (Shivhare and Rastogi, 2016; Liu et al., 2018). As mentioned before, the combination of SET and VICE allows the study and evaluation of events from the perspective of different stakeholders. This approach considers that they are involved in developing the event to adapt and modify it according to needs and to apply the concept of co-creation (Chen et al., 2020). 


\section{Method}

\subsection{Design of the research and approach}

The qualitative approach was based on 20 in-depth interviews conducted with stakeholders linked to the Viña Rock festival. The objective of the interview was to identify the perceptions from the stakeholders' point of view (host community, public and private sector) and to identify significant consequences of a health crisis regarding the celebration of the festival. To this end, the design of the interviews was carried out taking into account factors previously identified through the literature analysis regarding the social exchange moments that are identified (initial moment, exchange formation and post-interchange). Additionally, the interview considered questions related to socio-economic, cultural, and environmental impacts (Bimonte and Punzo, 2016) that determine the host community's well-being following the VICE model (Van Niekerk and Coetzee, 2013).

\subsection{Participants}

As mentioned before, the 20 interviewees represented the private sector (hotel managers, owners of catering establishments, media staff, festival staff and cleaning services), public sector (council staff, healthcare workers and security and fire services) and community (festival volunteers, local bands, and associations) participated in the study.

The selection of participants was carried out considering the following criteria: relation with the festival organization/management and a heterogeneous profile of participants for the final sample composition related to the stakeholder perspective. The stakeholders are divided into the host community, public and private sector due to its essential role (Van Niekerk and Getz, 2016) to determine the sociocultural impacts caused by the event and the effects of a health crisis, such as COVID-19 outbreaks. Considering these facts, the researchers made an initial list of potential interviewees considering their implication on the festival celebration-this first list comprised 48 individuals from the private sector, public sector, and community. These potential participants were contacted by email or phone directly by the researchers, and later they suggested appropriate people for this research using a horizontal networking approach (Geddes et al., 2018). Finally, 20 individuals agreed to participate in the study.

Table 2 reflects the participants' profiles. To ensure the anonymity and confidentiality of the participants in this study, we will distinguish interviewees using a code of letters, as indicated in Table I, along with a random number to differentiate each participant. In addition, participants are classified into internal and external, as proposed by Van Niekerk and Coetzee (2011).

Table I. Participants' profiles 


\subsection{Interview process and guide}

The interviews were conducted from 25 May to 27 September 2020. These interviews were done by phone considering the health crisis provoked by COVID-19. This method presents different strengths and is validated as an effective methodology (Holt, 2010; Cachia and Millward, 2011; Villacé-Molinero et al., 2021). Telephone interviewing was chosen because of the lockdown and the risk of being in contact face to face considering the COVID-19 outbreak and the prohibition for researchers to develop fieldwork during this time in Spain. The interviews lasted a mean of approximately $45 \mathrm{~min}$.

The interview was divided into three blocks considering the three moments of the exchange of the SET: (1) initial moment of the exchange; (2) exchange formation; (3) post-interchange and the emergence of a health crisis. The first block contemplated the perceptions about the impacts of the event celebration on the visitor's arrival and the expectations about the economic and sociocultural development associated with the event (Getz, 2008; González Reverté and Morales Pérez, 2017). The second block is focused on analysing the economic, sociocultural, and environmental impacts. We analysed the visitors' acceptance or not on this block, considering the stakeholders' previous experience (Rollins and Delamere, 2007; Chirieleison and Scrucca, 2017; Van Niekerk and Coetzee 2013; Dodds and Walsh, 2019; Liu et al., 2019). The third block is regarding managing the impacts from a personal impact and the future celebration of the event after a health crisis (Nepal, 2020; Rowen, 2020; Gössling et al., 2020; Kachanoff et al., 2020).

\subsection{Analysis}

Thematic analysis using data from the 20 depth interviews was carried out. This method allows identifying, analysing, and reporting patterns (themes) within the data (Braun and Clarke, 2006). This analysis involved searching for and identifying common threads that extend across an entire interview or set of interviews and fit very well with our research aim. The reason why this method of analysis was selected was that it lets researchers identify, organise, analyse, and propose patterns of relationship between themes, in this case, the sociocultural impacts caused by the festival from stakeholder perspectives and the effects of a health crisis (Braun and Clarke, 2006).

The analysis phases, according with Braun and Clarke (2006, p. 87), were as follows: (i) familiarisation with data; transcribing interviews, reading and rereading the data, noting down initial ideas; (ii) generating initial codes, coding interesting features of the data systematically across the entire data set, collating data relevant to each code; (iii) searching for themes, collating codes into potential themes, gathering all data relevant to each potential theme; (iv) reviewing themes, checking if the themes work in relation to the coded extracts and the entire data set, generating a thematic map; (v) defining and naming 
themes, ongoing analysis for refining the specifics of each theme and the overall story that the analysis tells, generating clear definitions and names for each theme; finally, (vi) producing the report, selection of vivid, compelling extract examples, final analysis of selected extracts, relating back of the analysis to the research question and literature, producing a report of the analysis.

The results have been structured into four blocks following the VICE model (visitors, industry, community and environment) and the three moments of the exchange considered by the SET (initial moment of the exchange; exchange formation; post-interchange and emergence a health crisis).

\section{Results}

This section reflects the main results from the qualitative study considering the thematic analysis approach based on SET and VICE model.

\subsection{Industry}

Events are often connected to tourism because there are strategies to attract visitors in the case of festivals, and infrastructure is developed to improve their capacity and ability to welcome visitors (Hodur and Leistritz, 2007). Therefore, these events often arise as a local initiative that becomes a tourist activity and generates significant economic impacts (O'Sullivan and Jackson, 2010).

Regarding the initial moment of exchange, the festival was created considering a local initiative focused on promoting local bands and improving their possibilities of giving concerts. During the first years of the event, the public was small, and most were local. The interviewees remark that the industry was little involved in the festival's development, generating little impact in economic terms.

At this stage and for more than 10 years now, the expectations of economic or cultural development are inherent to the festival itself. It attracts tens of thousands of people over 3 to 6 days and is, therefore, an injection at the local level of the aspects mentioned above (Interview 10, MS).

The most important part of the income goes to the organising company, and the rest of the jobs created are of low quality and short term. It means that there is an economic benefit in the end, but it is not as high as it could be by integrating all the actors and creating joint strategies (Interview 11, MS).

About the exchange formation, this event has become a mega-event during the last decade due to the massive increase in visitors, media coverage, and economic impacts (Getz, 2008). A considerable impact has accompanied this growth on the development of tourist demand, which has promoted the city as a 
tourist destination in connection with the event's celebration (Chirieleison and Scrucca, 2017).

The other stakeholders interviewed also confirmed that the festival brings economic benefits but mainly to some local businesses, especially food and drinks. However, from their point of view, economic benefits do not revert to the community because most of the incomes are directly going to the organising company. Almost all the stakeholders interviewed agreed on this:

The news speaks of 22 million euros, but the reality is that the City Council barely perceives economic benefits. The primary beneficiaries of this are businesses and supermarkets or banks [...] There is no clear commitment to the local economy. (Interview 20, C)

Additionally, interviewed participants concluded that the jobs created with the festival were of low quality and short term. In other words, jobs are created in the service sector, especially in restaurants and supermarkets. In addition, income is generated in the local community through rental accommodation, the sale of snacks, and showers for attendees. However, there is also an underground economy and the creation of jobs that are not legally declared, as the interviewees' point of view shows:

The expectations for economic development that have been generated in the last 5-10 years of the festival are enormous. Around this, not to say $80 \%$ of the town of Villarrobledo turns to offer a service. There is an enormous difference between the type of attendees that come to the event in the last five years because their precedence is national. (Interview 7, LB)

Concerning the post-interchange and emergence of a health crisis, the festival's holding depends on the health situation in April 2022 and on the planning and adopting measures to ensure health safety. There is concern from the stakeholders about the festival's development since it brings economic and cultural benefits. It will be necessary to develop a clear protocol of action to be transmitted to the stakeholders to establish the protocol to be followed to avoid the spread of COVID-19 through the event's celebration. As the interviewees said, the most important part is to improve the communication between the different stakeholders and collaboratively create strategies:

There are so many people involved in this that, in the end, it is complicated to coordinate effectively when each party goes its way. They need to improve their communication and strategise together (Interview $6, \mathrm{FV})$

Furthermore, one of the main concerns of the stakeholders in the organisation of the event itself, since not following clear guidelines and not transparently communicating them, increasingly makes it dangerous even to hold the event. However, from the different stakeholders' opinions, there is an evident disposition to adopt a protocol of celebration considering the measures adopted to avoid the propagation of COVID-19. Considering these results (RQ1), the 
principal impacts before the health crisis were linked to the development of the tourism industry, employment creation, additional incomes for local businesses, and entrepreneurship promotion. Regarding the health crisis in the industry arises. These impacts are the lack of efficient communication, economic losses, and reduced employment rate linked to the festival celebration.

\subsection{Community}

The host community's attitudes towards tourists are critical to the sustainable development of the tourist industry (Fan et al., 2018). Holding tourist events, therefore, promotes sociocultural and environmental impacts (Getz and Page, 2016). Getz (2005) considers that a key value of the events in the community's support is to analyse community perceptions of a festival case study. The sociocultural impacts are the interrelationship between tourists, tourist destination, and residents (González Reverté and Morales Pérez, 2017).

Regarding the initial moment of the exchange, the festival enriches the cultural life of the city. However, there is a perception by some stakeholders of a lack of collaboration and integration with the local community.

The festival enriches the city's cultural life, but it is not present all year round or contributes to the local community. It is something that happens on the spot. (Interview 6, FV)

Regarding the exchange formation, in terms of social and cultural impact, the main aspects that arise from the study's results are the cultural opportunity that the festival presents for the host community, the strength of identity with the city, and the trust and cohesiveness between community members. The interviews with comments like this one also confirm that:

It has marked many people. It is a festival, but it becomes a way of thinking and acting because in the city people can feel involved with the festival. (Interview 19, CS)

Rao (2001) suggests that festivals have positive public characteristics beyond revenue-generating because they provide a space where the local community members can get together and participate in mutually enjoyable activities. Festivals play an important role in creating trust and cohesiveness among community members (Chwe, 1998). The so-called hallmark events involve the participation of the local community and end up becoming part of the local identity. Therefore, a fundamental aspect is the festival's identity, connected to the city and the local community. Besides, interviewees highlighted that the festival celebration has enhanced cultural enrichment and is linked to their local community identity. However, it is necessary to integrate the local community more actively in their development. 
It seems that these are positive impacts that also improve the town's image, but I believe that the active participation of the local community should be further encouraged. (Interview 6, FV)

In this sense, expectations of economic and cultural development are inherent to the festival itself. On a cultural level, it allows the local population to participate in the festival by attending and interacting with different people and urban cultures. However, there are no associated initiatives (e.g., free concerts in different zones of the city to promote local participation or activities related to the event's culture) to encourage community participation.

This type of event in areas outside the festival site would allow participants to move to other neighbourhoods. It would spread the economic and cultural impact, encouraging tourism into other city areas beyond the festival site. The local community believes that the festival encourages visitors to stay in and around the venue, meaning that the positive impacts are not distributed evenly across all city areas.

Lately, they do not go out of the compound to the population. Everything is set up to not leave the festival area, from tents, camping, showers, etc. It is very autonomous, and that is what the city is missing. It is also missing attachment. Too much merchandising and internal supply. (Interview 12, OCS)

Results show experiences on a personal level concerning the festival, connections between people who develop activities during the festival and the public who have the possibility of extending their musical knowledge thanks to the festival. Therefore, a need to establish concrete activities related to the local population is detected to promote their participation and integration into the event.

The city council is becoming more personal and financially. The citizens give a lot and bet on the festival holding. [...] The company and the City Council are involved in the event's activities, but there is no clear commitment to bring the cultural richness of Viña Rock to the local population. (Interview 20, C)

Regarding the information related to the festival's results indicators, no evidence has been found of their existence beyond data provided by the organisers. The interviews have shown the need to generate annual indicators that help better understand the population's impacts. In connection with this point, Getz (2008) considers it necessary to establish outcome indicators for social policies linked to festivals so that positive sociocultural impacts can be enhanced and social benefits generated through holding these events.

The stakeholders consider the holding of events a global public health problem about the post-interchange and emergence of a health crisis. Therefore, there is a need to establish guidelines and protocols to ensure that the spread 
of COVID-19 is stopped (Nepal, 2020; Rowen, 2020), as we can say considering the following answer:

I think the festival should continue to be held, but the measures need to be clear and not being communicated properly. They are very positive, but there are so many people involved in this that, in the end, it is challenging to have effective coordination when each party goes its way. They need to improve their communication and create strategies together. (Interview 6, FV)

The main perceived impacts on the community before the health crisis are strengthening cultural life, identity creation, and brand strategies linked to transmitting trust and cohesiveness. After the health crisis, the impacts detected were the public health problems linked to the massive arrival of visitors and the negative impacts on the cultural life and the experience regarding the cancellation of the event (RQ2).

\subsection{Visitors}

Previous studies have focused on analysing visitors' perspectives (Chen et al., 2018; Kruger and Saayman, 2018). Considering the VICE model, visitors can be domestic or international and impact the local economy (Van Niekerk and Coetzee, 2013). The perception of stakeholders about visitors by applying SET allows us to obtain results considering the implication of visitors and their importance to the celebration of the event.

Regarding the initial moment of exchange, the festival was initially planned to attract between 1,000 and 5,000 people as there was no infrastructure or resources to hold a more significant festival. In this sense, the current forecasts of success were not contemplated at the beginning. It was a festival that arose spontaneously in the city and therefore was held in different spaces as the public increased, until finally moving to the fairground. Besides, the interviewees remark that the official statistics are not well calculated:

When all this began, few people attended, and it was usually not thought that it would be possible to call such a large audience. It was a relatively unattended festival that emerged spontaneously (Interview 4, FS).

There are not many people as the official statistics indicate. Few people come, but if you multiply the tickets sold for each festival day, you get those numbers when fewer people come to Villarrobledo (Interview 11, MS).

Considering the exchange formation, the local population has a general acceptance of the festival's visitors from the stakeholders' point of view. However, it should be noted that residents over the age of 60 have more incredible difficulty in considering the massive arrival of visitors as positive. 
There are always people who disagree, but mainly I think that, because of the lack of toilets, showers, cleaning, etc., that make everything so dirty, people are already used to seeing the usual mohawks, piercings, and tattoos. In my opinion, it is a pity the pilgrimage of people who arrive at the station and go loaded with tents and backpacks to the enclosure because it could be more coordinated the arrival of train and bus with the local bus service (Interview 2, AS).

About the post-interchange and emergence of a health crisis, it is evident that the experience of the visitors receives a negative impact because of the different security measures implemented to contain the infection (i.e., social distancing, vaccinate certificates):

The festivals, the concentrations of people, are going to be more conditioned. The situation can be saved, and it can be saved if Viña Rock continues to exist as it has until today [...]. If you go to a concentration or a party and you cannot be in contact with people because you must respect a safety distance, etc. the experience is affected"(Interview 19, CS)

Finally, the information the visitors receive is scarce, and the communication between the enterprise that organises the event and visitors with festival passes and tickets is not clear. It is important to remark that the date of the festival has been changed three times since the health crisis with between one- and two months' notice. Regarding the impacts perceived before the health crisis, there was a negative perception of the mass arrival of visitors. The acceptance of visitors was higher than years before. The impacts after the health crisis show that social distancing is not well received because it causes negative impacts on the visitors' experience. Besides, the stakeholders remark that the easiest way to reestablish events is to ask for vaccination certificates (RQ3).

\subsection{Environment}

Environment management related to the festival includes how the waste, traffic and noise are managed. The celebration of mega-events generates at an environmental level a series of impacts that, in many cases, are difficult to manage due to the difficulty that the mass attendance of festival-goers represents (Collins and Cooper, 2016; Dodds and Walsh, 2018).

Regarding the initial moment of the exchange, recycling, noise, and traffic control measures were not a cause for concern because fewer visitors would be lower.

During the exchange formation, discomfort is linked to the waste treatment and the traffic and noise level increase due to the Viña Rock festival. This fact was confirmed during the interviews: 


\begin{abstract}
People who live in the neighbourhoods where Viña Rock is held demand that the economic impact will improve the streets and infrastructure because they are practically three days with 24-hour noise. They sacrifice themselves [...] damage is caused to street furniture and much dirt. (Interview 20, C)
\end{abstract}

In addition, the mass arrival of visitors is linked to the production of a large amount of waste that is difficult to manage and a considerable increase in traffic and noise. Regarding the environmental aspects, interviews suggested that waste management measures applied by the city council should be significantly improved as they remain in place for 15 days after the festival. Furthermore, the main material used is plastic, which is not collected and separately treated as there is no sustainable waste management. These aspects are reflected in the interviews:

\begin{abstract}
Waste remains on the streets for 15 days, next to houses that go about people daily lives in their neighbourhood. Moreover, the waste is almost all plastic. It is not recycled. There is no sustainable waste management, i.e., it is not considered. It all ends up in the same container. It is a constant waste of plastic and everything. Traffic control also affects the festival, as there are many drug controls, etc., during the days of the festival, the people of the town rarely travel by car because it is complicated. Imagine a town of about 26,000 people suddenly getting about 200,000 more than usual. It is impossible. It is unmanageable. The noise is also striking because the venue was far from the inner city and the housing area, but new houses have been built in that area, and it is horrible for the people who live in that area. (Interview 11, MS).
\end{abstract}

This participation is linked to the development of the festival during COVID-19. During the post-interchange and emergence of a health crisis, it was considered that measures taken by the festival organisation had not been communicated to stakeholders. There is a need for collaboration between local community institutions and the organising company to disseminate the agreements. It would enable the event to be held in total safety without harming the local population by increasing the number of infections.

It is being assessed. There are no specific data because even the health authorities themselves do not know what is happening. Maybe this year, it will have to be suspended, but if we get to that case and it is suspended, we hope it can be restored to normal with the vaccine. The festivals, the concentrations of people, are more conditioned. The situation can be saved, and it can be saved if Viña Rock continues to exist as it has until today [...]. If you go to a concentration or a party and you cannot contact people because you must respect a safe distance, etc., the experience is affected. (Interview 19, CS)

The celebration of events and festivals contributes to the dissemination of COVID-19, so it is necessary to establish external and internal policies to 
control and establish protocols for action in the organisation of events and festivals (Wang et al., 2020). These measures need to consider the different stakeholders and carry out a more fluid and integral communication and collaboration system.

There is no honest communication. The City Council is afraid to cancel the festival because it is afraid that the company will denounce it and sanction it. We are waiting for the regional government to confirm its cancellation or postpone it [...] I think the collaboration that institutions have with the festival is not adequate [...] The resources generated from selling tickets, or renting premises around the festival, is used not only for the benefit of the company but also to improve the health conditions of the festival. The company is responsible for monitoring and collecting payment for the stalls, setting up the stages and paying for urban waste collection. Everything else (engineers, security, electricians, local police) is provided by the City Council. The company has a contract with the Town Hall where it receives 1 euro for the sale of each ticket produced but has not yet reverted to the Town Hall. (Interview 20, C)

The previous impacts on the environment were linked to waste, traffic and noise management. The stakeholders highlight the necessity of creating an environmental plan to solve the issues associated with the celebration of this festival in the future (RQ4).

\section{Conclusions, limitations and future research}

\subsection{Conclusions}

This study allowed developing a model from the initial proposal based on both VICE model (Van Niekerk and Coetzee, 2013) and SET (Monterrubio et al., 2018). The new proposal has confirmed the theoretical support for a better understanding of stakeholder perceptions about the impacts of a music festival under a new risk scenario. The principal contribution of this research is the creation of a framework considering SET and VICE model to analyse the risks associated to a health crisis. This framework is an evidence-based structural and explanatory model dealing with the main factors that could help understand stakeholders' perspectives about the events' impacts caused in industry, community, visitors, and environment in three different moments of the exchange. Additionally, results have allowed two distinctive social exchange in two relevant stages: before and after a health crisis. This new analytical framework is crucial because it identifies features that influence the festival impacts and their application to a new risk scenario and addresses a gap in research (Figure 2).

Figure 2. Festival impacts and social exchange before and after a health crisis 
SOCIAL EXCHANGE BEFORE A HEALTH CRISIS

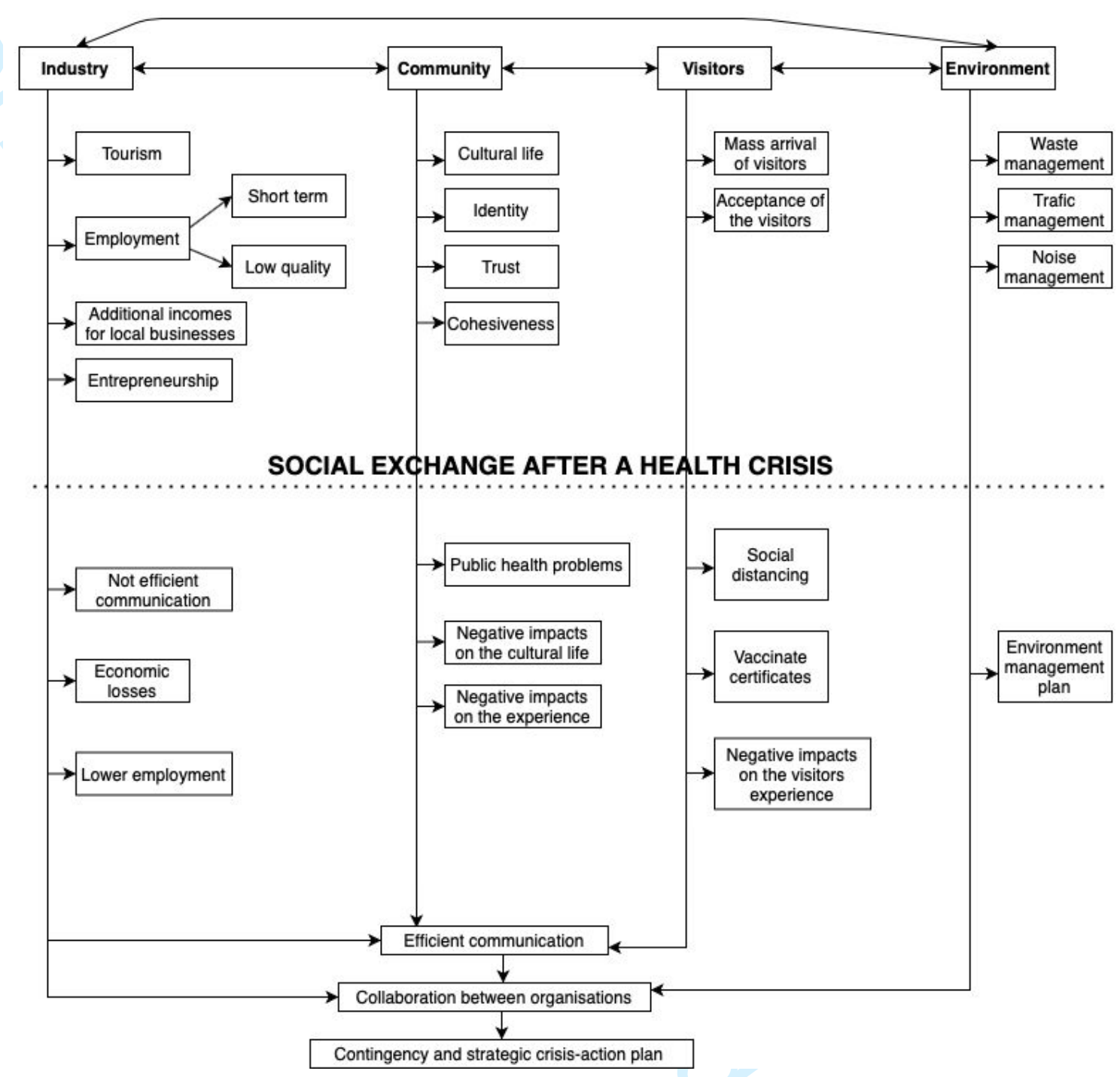

Before the health crisis, especially during the moment of exchange, the perceptions surrounding the industry impacts of the Viña Rock festival were mainly positive. These results reflect that before the health crisis, the local community and entrepreneurs mainly perceived the positive impacts of the festival in terms of employment and business benefits. In contrast, from the government point of view, it was stressed that this economic impact does not directly affect the population's well-being.

Concerning the perception of the impacts on the community, before the health crisis, the participants also highlighted its benefits as mainly related to strengthening the community's confidence and identity and the more significant cultural offerings available. Stakeholders' perceptions of the impacts on the environment are the most negative. All the participants stressed that there had been problems related to waste management, noise, and traffic since the start of the festival. These aspects are detailed by Van Niekerk and Coetzee (2013), who confirm that the 'remediation undertaken after the festival should be noted, 
as well as precautions that should be put in place the following year to help minimise environmental degradation'(Van Niekerk and Coetzee, 2013: p. 353).

The most recent health crisis linked to COVID-19 has meant a change of global scenario, and many festivals in 2020 have been cancelled or postponed; it is necessary to identify the main issues and possibilities for the future of festivals (Davies, 2020). The results reflect that the agents' perceptions of the impact that COVID-19 will have on the festival are negative. The perception of a lack of information and communication (Dodds et al., 2020) is noteworthy, causing high levels of uncertainty among the agents. The perception of the impacts on the industry is related to the reduction in employment and economic activity generated. The perception of the impacts from the community point of view is also negative, highlighting above all health concerns and the possible negative experience of those attending if the festival is held. The perception of the environmental impacts is not different from that before the health crisis period, and the agents talk about the need for an environmental management plan.

Cooperation among stakeholders is considered a key strategy that festivals employ to increase their sustainability (Karlsen and Stenbacka, 2009), and the role played by the organisers in the success of these events is remarkable (Presenza and locca, 2012). It is even more relevant in the case of festivals that have been put on regularly over a long period, as the overall complexity increases, especially in terms of revenue, expenditure and the numbers of people involved (Presenza and locca, 2012). Although the importance of stakeholder cooperation in organising a music festival is evident, the weight and frequency of stakeholder relationships are not noticeable. There is no shared information about the festival manager's decision or strategies for the pandemic scenario. A sense of absence of communication has been detected from the interviews. The importance of stakeholder cooperation has been widely studied. Identifying and engaging the broadest range of stakeholders presents an opportunity for festival management to achieve specific objectives and minimise adverse impacts, and advocate broader social responsibility (Van Niekerk and Getz, 2016).

The most important theoretical contribution is that stakeholder groups or individuals inside the organisation that affect or are affected by the decisions of the festival (internal stakeholders) and outside the festival organisation but still affected) need to be managed differently, and festival organisers should be conscious of this (external stakeholders). The interviews reflected a considerable gap between internal and external stakeholders, leading to poor communication and planning of the event.

Regarding the practical implications, the results show the interactions between the dimensions considered, thus demonstrating the systemic nature of music festivals, where internal and external stakeholders interact and complement each other. Figure 2 shows a conceptual system where it can be observed that collaboration among organisations is a theme that plays a central role in the management of music festivals because it constitutes the primary source of strategic resources and direction from the stakeholder's knowledge and 
experience. In a health crisis context, developing initiatives that involve the stakeholders to create mutual aid and protection strategies (Davies, 2020).

\subsection{Limitations and future research}

The nature of the methodology employed in this paper entails some restrictions worth mentioning. The main limitation is related to the 'Vistors' section of the VICE model. The festival has been rescheduled, and there was no possibility of interviewing the visitors. Any future research should consider the perception of visitors.

Future research could focus on understanding more about internal stakeholder perceptions, which would enrich and extend the information about festivals and health crises. Such data would provide a more comprehensive picture of the topic.

\section{REFERENCES}

Alonso-Almeida, M. d.M. and Rodríguez-Antón, J. M. (2020), "The Role of Institutional Engagement at the Macro Level in Pushing the Circular Economy in Spain and Its Regions". Int. J. Environ. Res. Public Health, Vol. 17 No. 6 2086. https://doi.org/10.3390/ijerph17062086

Bagiran, D. and Kurgun, H. (2013), "A research on social impacts of the Foça Rock Festival: the validity of the Festival Social Impact Attitude Scale", Current Issues in Tourism, Vol. 19 No. 9, pp.930-948. https://doi.org/10.1080/13683500.2013.800028

Barber, N., Kim, Y. and Barth, S. (2014), "The Importance of Recycling to U.S. Festival Visitors: A Preliminary Study", Journal of Hospitality Marketing \& Management, Vol. 23 No. 6, pp.601-625. https://doi.org/10.1080/19368623.2014.844661

Bimonte, S. and Punzo, L. (2016), "Tourist development and host-guest interaction: An economic exchange theory", Annals of Tourism Research, No. 58, pp.128-139. https://doi.org/10.1016/j.annals.2016.03.004

Braun, V. and Clarke, V. (2006), "Using thematic analysis in psychology", Qualitative Research in Psychology, Vol. 3 No. 2, pp.77-101. https://doi.org/10.1191/1478088706qp063oa

Cachia, M., and Millward, L. (2011). "The telephone medium and semistructured interviews: A complementary fit". Qualitative Research in Organizations and Management: An International Journal. https://doi.org/10.1108/

Casady, C. B., \& Baxter, D. (2020). "Pandemics, public-private partnerships (PPPs), and force majeure| COVID-19 expectations and implications". Construction Management and Economics, Vol. 38 No. 12, pp. 1077-1085.

Chen, Y., King, B. and Lee, H. (2018), "Experiencing the destination brand:

Behavioral intentions of arts festival tourists", Journal of Destination 
Marketing \& Management, No. 10, pp.61-67. https://doi.org/10.1016/j.jdmm.2018.06.004

Chen, Z., King, B. and Suntikul, W. (2020). "Co-creation of value for cultural festivals: behind the scenes in Macau", Tourism Recreation $\begin{array}{lllll}\text { Research, Vol. } 45 & \text { No. } 4, & \text { pp. } & \text { 430-444. }\end{array}$ https://doi.org/10.1080/02508281.2020.1737793

Chirieleison, C. and Scrucca, L. (2017), "Event sustainability and transportation policy: A model-based cluster analysis for a cross-comparison of hallmark events", Tourism Management Perspectives, No. 24, pp.72-85. https://doi.org/10.1016/j.tmp.2017.07.020

Chwe, M. (1998) "Culture, circles, and commercials: Publicity, common knowledge, and social coordination", Rationality and Society Vol. 10 No. 1, pp.47-75. https://doi.org/10.1177\%2F104346398010001002

Collins, A. and Cooper, C. (2016) "Measuring and managing the environmental impact of festivals: the contribution of the Ecological Footprint", Journal of Sustainable Tourism, Vol. 25 No. 1, pp.148-162. https://doi.org/10.1080/09669582.2016.1189922

Davies, K. (2020), "Festivals Post Covid-19", Leisure Sciences, pp.1-6. https://doi.org/10.1080/01490400.2020.1774000

Dodds, R. and Walsh, P. (2018), "Assessing the factors that influence waste generation and diversion at Canadian festivals", Current Issues in Tourism Vol. 22 No. 9, pp.2348-2352. https://doi.org/10.1080/13683500.2018.1461813

Dodds, R., Novotny, M. and Harper, S. (2020), "Shaping our perception of reality: sustainability communication by Canadian festivals", International Journal of Event and Festival Management, Vol. 11 No. 4, pp.473-492. https://doi.org/10.1108//JEFM-03-2020-0012

Duran, E., Hamarat, B. and Özkul, E. (2014), "A sustainable festival management model: the case of International Troia festival", International Journal of Culture, Tourism and Hospitality Research, Vol. 8 No. 2, pp.173193. https://doi.org/10.1108/IJEFM-03-2020-0012

Fan, D., Liu, A. and Qiu, R. (2018), "Revisiting the relationship between host attitudes and tourism development: A utility maximisation approach", Tourism Economics Vol. 25 No. 2 pp.171-188. https://doi.org/10.1177\%2F1354816618794088

Getz, D. (2008), “Event tourism: Definition, evolution, and research”, Tourism Management, Vol. 29 No. 3, pp.403-428. https://doi.org/10.1016/j.tourman.2007.07.017

Getz, D. and Page, S. (2016), "Progress and prospects for event tourism research", Tourism Management, No. 52, pp.593-631. https://doi.org/10.1016/j.tourman.2015.03.007 
Gil-Alana, L. and Poza, C. (2020), "The impact of COVID-19 on the Spanish tourism sector", Tourism Economics p.135481662095991. https://doi.org/10.1177\%2F1354816620959914

González Reverté, F. and Morales Pérez, S. (2017), "El impacto cultural y social de los eventos celebrados en destinos turísticos. La percepción desde el punto de vista de los organizadores", Cuadernos de Turismo, p.339. https://doi.org/10.6018/turismo.40.309741

Gössling, S., Scott, D. and Hall, C. (2020) "Pandemics, tourism and global change: a rapid assessment of COVID-19", Journal of Sustainable Tourism, Vol. 29 No. 1, pp.1-20. https://doi.org/10.1080/09669582.2020.1758708

Gursoy, D., Kim, K. and Uysal, M. (2004), "Perceived impacts of festivals and special events by organisers: an extension and validation", Tourism Management, Vol. 25 No. 2, pp.171-181. https://doi.org/10.1016/S0261$\underline{5177(03) 00092-X}$

Homans, G. C. (1961), "Social behavior: Its elementary forms", Social Behavior, pp. 488-531.

Holt, A. 2010. "Using the Telephone for Narrative Interviewing: A Research Note." Qualitative Research $10 \quad(1)$ : 113-121. doi:10.1177/1468794109348686.

Hoque, A. Shikha, F. A. Hasanat, M. W. Arif, I. and Hamid, A. B. A., (2020), "The effect of Coronavirus (COVID-19) in the tourism industry in China", Asian Journal of Multidisciplinary Studies, Vol. 3 No. 1, pp. 52-58.

Jitsuk, N. C., Suttirat, P. and Modchang, C. (2020), "Effect of the Songkran festival on COVID-19 transmission in Thailand", Asian Pacific Journal of Tropical Medicine, Vol. 13 No. 7, pp. 331.

Kachanoff, F., Bigman, Y., Kapsaskis, K. and Gray, K. (2020), "Measuring Realistic and Symbolic Threats of COVID-19 and Their Unique Impacts on Well-Being and Adherence to Public Health Behaviors", Social Psychological and Personality Science p.194855062093163. https://doi.org/10.1177\%2F1948550620931634

Karlsen, S. and Stenbacka Nordström, C. (2009), "Festivals in the Barents Region: Exploring Festival-stakeholder Cooperation", Scandinavian Journal of Hospitality and Tourism Vol. 9 No. 2-3, pp.130-145. https://doi.org/10.1080/15022250903157447

Kim, K., Uysal, M. and Sirgy, M. J. (2013). "How does tourism in a community impact the quality of life of community residents?", Tourism $\begin{array}{llll}\text { management, No. } & 36, & \text { pp. } & \text { 527-540. }\end{array}$ https://doi.org/10.1016/j.tourman.2012.09.005

Kinnunen, M. and Haahti, A. (2015), "Visitor discourses on experiences: reasons for festival success and failure", International Journal of Event and Festival Management, Vol. 6 No. 3, pp.251-268. https://doi.org/10.1108/lJEFM$\underline{01-2015-0003}$

Kruger, M. and Saayman, M. (2018)," 'All that jazz': the relationship between music festival visitors' motives and behavioural intentions", Current Issues in Tourism, Vol. 22 No. 19, pp.2399-2414. https://doi.org/10.1080/13683500.2018.1451496 
Liu, C., Lin, W., Wang, Y. and Chen, S. (2018), "Sustainability indicators for festival tourism: A multi-stakeholder perspective", Journal of Quality Assurance in Hospitality \& Tourism, Vol. 20 No. 3, pp.296-316. https://doi.org/10.1080/1528008X.2018.1530165

Ludvigsen, J. A. L. and Hayton, J. W. (2020) "Toward COVID-19 secure events: considerations for organising the safe resumption of major sporting events", Managing Sport and Leisure, pp. 1-11. http://doi.org/10.1080/23750472.2020.1782252

Manjavacas, F. (2019). "El Viña Rock que no va de conciertos", available at: https://www.eldiario.es/castilla-la-mancha/vina-rock-vaconciertos_1_1561206.html (Accessed 13 March 2021).

McCloskey, B., Zumla, A., Ippolito, G., Blumberg, L., Arbon, P., Cicero, A., Endericks, T., Lim, P. and Borodina, M. (2020) "Mass gathering events and reducing further global spread of COVID-19: a political and public health dilemma", The Lancet, Vol. 395 No. 10230, pp.1096-1099. https://doi.org/10.1016/S0140-6736(20)30681-4

Mohanty, P., Dhoundiyal, H. and Choudhury, R. (2020), "Events Tourism in the Eye of the COVID-19 Storm: Impacts and Implications". SSRN Electronic Journal, https://dx.doi.org/10.2139/ssrn.3682648

Monterrubio, C., Sosa Ferreira, A. and Osorio García, M. (2018), "Impactos del turismo residencial percibidos por la población local: una aproximación cualitativa desde la teoría del intercambio social", LiminaR Estudios Sociales y Humanísticos, Vol. 16 No. 1, pp.103-118.

https://doi.org/10.29043/liminar.v16i1.567

Morales Pérez, S. and Pacheco Bernal, C. (2017), "Residents' Perception of the Social and Cultural Impacts of a Public Music Festival in Catalonia", Almatourism-Journal of Tourism, Culture and Territorial Development, Vol. 8 No. 7, pp.21-36. https://doi.org/10.6092/issn.20365195/6748

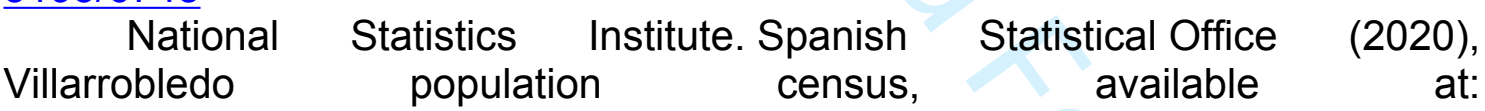
https://www.ine.es/dyngs/INEbase/es/operacion.htm?c=Estadistica_C\&cid=125 4736176951\&menu=ultiDatos\&idp=1254735572981 (Accessed ${ }^{-} 13$ March 2021).

Nepal, S. (2020), "Adventure travel and tourism after COVID-19 - business as usual or opportunity to reset?", Tourism Geographies, Vol. 22 No. 3, pp.646-650. https://doi.org/10.1080/14616688.2020.1760926

O'Sullivan, D. and Jackson, M. (2002) "Festival Tourism: A Contributor to Sustainable Local Economic Development?", Journal of Sustainable Tourism, Vol. 10 No. 4, pp.325-342. https://doi.org/10.1080/09669580208667171

Parent, M. M., \& Smith-Swan, S. (2013). "Bidding for an event". Managing major sports events: Theory and practice, 12-26.

Picard, D. and Robinson, M., (2006), "Remaking worlds: Festivals, tourism and change", Festivals, tourism and social change: Remaking worlds pp.1-31. 
Polyzos, S. Samitas, A. and Spyridou, A. E. (2020), "Tourism demand and the COVID-19 pandemic: an LSTM approach", Tourism Recreation Research, pp.1-13. https://doi.org/10.1080/02508281.2020.1777053

Ponting, S.S.-A. (2021), "'I am not a party planner!": setting a baseline for event planners' professional identity construction before and during COVID19", Journal of Hospitality and Tourism Insights, Vol. 4 No. 2, pp. 205223. https://doi.org/10.1108/JHTI-09-2020-0164

Praveen, S. and Deepak, R. (2016), "Environmental impact assessment due to festivals", International Journal of Engineering Technology Science and Research, No. 3 pp. 166-172.

Presenza, A., \& locca, S. (2012.), "The weight of stakeholders on festival management. The case of music festivals in Italy", Pasos - Revista de Turismo y Patrimonio cultural, Vol. 10 No. 2, pp.25-35. https://doi.org/10.25145/j.pasos.2012.10.024

Quinn, B. (2013). Key concepts in event management. Sage.

Rollins, R. and Delamere, T. (2007) "Measuring the social impact of festivals", Annals of Tourism Research, Vol. 34 No. 3, pp.805-808. http://dx.doi.org/10.1016/j.annals.2007.01.004

Rowen, I. (2020) "The transformational festival as a subversive toolbox for a transformed tourism: lessons from Burning Man for a COVID-19 world", Tourism Geographies, pp.1-8. https://doi.org/10.1080/14616688.2020.1759132

Scholtz, M. Viviers, P. A. and Maputsoe, L. (2019) "Understanding the residents' social impact perceptions of an African Cultural Festival: the case of Macufe", Journal of tourism and cultural change, Vol. 17 No. 2, pp.166-185. https://doi.org/10.1080/14766825.2018.1426592

Shivhare, P. and Rastogi, D. (2016) "Environmental impact assessment due to festivals", International Journal of Engineering Technology Science and Research, No. 3, pp.166-172.

Stienmetz, J. Kim, J. J. Xiang, Z and Fesenmaier, D. R. (2020) "Managing the structure of tourism experiences: Foundations for tourism design", Journal of Destination Marketing \& Management, 100408. https://doi.org/10.1016/j.jdmm.2019.100408

Van Niekerk, M. (2017), "Contemporary issues in events, festivals and destination management", International Journal of Contemporary Hospitality Management. https://doi.org/10.1108/IJCHM-01-2017-0031

Van Niekerk, M. and Coetzee, W. J. L. (2011) "Utilising the VICE model for the sustainable development of the Innibos Arts Festival", Journal of Hospitality Marketing \& Management, Vol. 20 No. 3-4, pp.347-365. https://doi.org/10.1080/19368623.2011.562422

Van Niekerk, M. and Coetzee, W. J. L. (2013), "Utilising the VICE model for the sustainable development of the Innibos Arts Festival", Event Tourism and Cultural Tourism. Routledge, pp.115-133. https://doi.org/10.1080/19368623.2011.562422

Van Niekerk, M. and Getz, D. (2016), "The identification and differentiation of festival stakeholders", Event Management, Vol. 20 No. 3, pp.419-431. https://doi.org/10.3727/152599516X14682560744910

Villacé-Molinero, T., Fernández-Muñoz, J. J., Orea-Giner, A., \& FuentesMoraleda, L. (2021). "Understanding the new post-COVID-19 risk scenario: Outlooks and challenges for a new era of tourism". Tourism Management, Vol. 86, 104324. https://doi.org/10.1016/j.tourman.2021.104324 
Wang, Y. Fang, Z. and Gao, W. (2020), "COVID-19's impact on China's economy based on data of spring festival travel rush". Available at SSRN 3554638. https://dx.doi.org/10.2139/ssrn.3554638

Weidenfeld, A. and Leask, A. (2013), "Exploring the relationship between visitor attractions and events: definitions and management factors", Current Issues in Tourism, Vol. 16 No. 6, pp. 552-569. https://doi.org/10.1080/13683500.2012.702736

Wen, J. Kozak, M. Yang, S. and Liu, F. (2020). "COVID-19: potential effects on Chinese citizens' lifestyle and travel", Tourism Review. https://doi.org/10.1108/TR-03-2020-0110

Yolal, M. Gursoy, D. Uysal, M. Kim, H. L. and Karacaoğlu, S. (2016), "Impacts of festivals and events on residents' well-being", Annals of Tourism Research, No. 61, pp.1-18. https://doi.org/10.1016/j.annals.2016.07.008

Zhang, J. C. Byon, K. K. Xu, K. and Huang, H. (2020), "Event impacts associated with residents' satisfaction and behavioral intentions: a pre-post study of the Nanjing Youth Olympic Games", International Journal of Sports Marketing and Sponsorship. https://doi.org/10.1108/IJSMS-03-2019-0027 
Table I. Participants' profiles

\begin{tabular}{|l|l|l|l|l|}
\hline Type & $\begin{array}{l}\text { Number of } \\
\text { participants }\end{array}$ & Code & $\begin{array}{l}\text { Type of } \\
\text { stakeholder }\end{array}$ & $\begin{array}{l}\text { Internal (I) } \\
\text { External (E) }\end{array}$ \\
\hline Hotel managers & 2 & HM & Private sector & E \\
\hline $\begin{array}{l}\text { Owners of catering } \\
\text { establishments }\end{array}$ & 2 & OCS & Private sector & E \\
\hline Healthcare workers & 4 & HW & Community & E \\
\hline Festival volunteers & 2 & FV & Community & I \\
\hline Council staff & 2 & C & Public sector & E \\
\hline Media staff & 2 & MS & Private sector & E \\
\hline $\begin{array}{l}\text { Security and fire } \\
\text { services }\end{array}$ & 2 & SFS & Public sector & E \\
\hline Festival staff & 1 & FS & Private sector & I \\
\hline Associations & 1 & AS & Community & E \\
\hline Local band & 1 & LB & Community & E \\
\hline Cleaning services & 1 & CS & Private sector & E \\
\hline
\end{tabular}

